\title{
Factors influencing Research Engagement among Medical students in the United Kingdom (REMED- UK): protocol for a prospective, observational, national, multi-centre questionnaire - study
}

Temidayo Osunronbi ( $\square$ academia@melaninmedics.org )

Melanin Medics

William Adeboye

Melanin Medics

David Faluyi

Melanin Medics

Jasmine Sofela

Melanin Medics

Agbolahan Sofela

Melanin Medics

\section{Method Article}

Keywords: Medical students, research, diversity, equality, academia

Posted Date: March 22nd, 2021

DOI: https://doi.org/10.21203/rs.3.rs-350355/v1

License: (c) (i) This work is licensed under a Creative Commons Attribution 4.0 International License.

Read Full License 


\section{Abstract}

Introduction: There has been a decline in the number of academic clinicians in the UK. Also, there is sex and ethnic inequalities in research opportunities amongst UK clinicians. The decision to get involved in research as a clinician is usually made as a medical student. Hence, this study aims to investigate the factors affecting UK medical students' involvement in research, and to understand their perceptions of research, motivation for and the barriers to their engagement in research.

Methods: This study is a prospective, observational, national, multi-centre study that will utilise an online questionnaire using the Qualtrics ${ }^{\mathrm{TM}}$ survey tool. Medical students that are at least 18 years old and enrolled in a UK medical school in the 2020/21 academic year are eligible to partake in this study. The following data will be collected: demographic, research experience, research perception, research selfefficacy, motivation, and barriers to engaging in research. The outcome measures are: number of research projects, publications, presentations, and successful grant applications.

Conclusion: This study will produce evidence-based reports that will guide UK medical schools and relevant organisations in developing resources and programmes that will increase the number of future academic clinicians and resolve inequalities in research opportunities and engagement amongst future clinicians.

\section{Introduction}

Research can contribute to the creation of new knowledge that leads to advancement in clinical care and practice. In the United Kingdom (UK), the General Medical Council 'Outcomes for graduates' states that newly qualified doctors must be able to apply scientific methods and approaches to medical research and be proficient in evidence-based medicine within their clinical field [1]. Clinicians should participate in research because compared to a purely basic scientist, they regularly encounter clinical problems that may inspire relevant questions for scientific research. Also, academic clinicians can bridge the gap between science and practice, by translating research findings into clinical settings [2].

Recent reports indicate a decline in the number of clinical academics in the UK in the last few decades [3-5]. Also, the ethnic and gender profile of the clinical academic workforce is not reflective of the wider population of licensed doctors. A 2018 report indicates that in the UK, there is a disproportionately low number of Black, Asian, and ethnic minority (BAME) and/or female clinicians in the clinical academic workforce and the upper echelons of research leadership [5]. A recent report by the Royal College of Physicians indicates that female clinicians and BAME clinicians have reduced access to research opportunities compared to their male/white counterparts [6]. It is believed that a greater balance in terms of gender and ethnicity in the healthcare workforce may improve patient outcomes, including those of deprived populations and ethnic minorities [7].

For most clinicians, the decision of whether to pursue a research career is made before they graduate from medical school [8]. Furthermore, early engagement in research has been reported to enhance 
medical students' research-related skills, stimulate their research interest, and is positively associated with sustained scientific activity and productivity after medical school graduation $[9,10]$. Hence, medical school provides a fertile ground to initiate programmes that will increase the number of future academic clinicians and resolve the gender and ethnic imbalance in research engagement amongst clinicians. However, there is little empirical research conducted in the UK to guide the development of such programmes.

To stimulate medical students and keep them interested in research, it is important to understand their motivation for and the barriers preventing their participation and attainment in research. Hence, the primary aim of this study is to investigate the factors influencing research opportunities and attainments amongst UK medical students. Also, the study will investigate the perception of research, motivation for and barriers to research engagement amongst UK medical students.

\section{Methods}

\section{Study design}

REMED-UK study is a prospective, observational, national, multi-centre study that will utilise an online questionnaire using the Qualtrics ${ }^{\mathrm{TM}}$ survey tool. This study is being run by Melanin Medics, a UKregistered charitable organisation that aims to increase diversity in medicine.

Ethics approval: This study received ethical approval from the Faculty of Health Research Ethics and Integrity Committee, University of Plymouth on 9 February 2021 (Ethics approval reference: 2570).

\section{Sampling}

Inclusion criteria: Every medical student enrolled in medical schools listed in the UK's Medical Schools Council at the start of the 2020/21 academic year.

Exclusion criteria: Any student that is unwilling or unable to give informed consent or does not meet the inclusion criteria.

The UK National Research Collaborative Model[11] will be used to distribute the questionnaire to medical students currently enrolled in medical schools listed by the Medical Schools Council at the start of the 2020/21 academic year. The survey will be disseminated through emails and various social media platforms. Prospective data will be collected over eight weeks (22 March to 16 May 2021).

Sample size: $\geq 381$ medical students. Calculated using Raosoft ${ }^{\circledR}$ Sample Size Calculator using the following parameters: margin of error (5\%), confidence interval (95\%), population size (45000), response distribution (50\%).

Questionnaire 
An initial questionnaire was created by members of the REMED-UK steering committee based on literature findings $[10,12,21-26,13-20]$. The initial questionnaire was sent to the REMED-UK regional leads (students across various UK medical schools) for feedback. The questionnaire was modified based on the received feedback.

The questionnaire (Appendix 1) has the following domains:

1. Demographics

2. Research experience and achievements (since starting medical school)

3. Perception of research

4. Research self-efficacy

5. Career interest

6. Motivation for research

7. Barriers to research

\section{Data analysis}

Pre-processing steps will include re-categorising free text entries into existing similar data categories and grouping free text entries into new data categories. Statistical analysis will be conducted on IBM SPSS Statistics 26 software. Variables with less than $80 \%$ responses will be excluded from the analysis.

Descriptive statistics will be presented as mean \pm standard deviation for parametric data, and median \pm interquartile range for non-parametric data. Frequencies will be presented as both absolute numbers and percentages.

Binary logistic regression analysis will be utilised to test for associations between categorical outcomes (binary) and the independent variables. Multinomial logistic regression analysis will be utilised if the categorical outcome has more than two categories. Multiple linear regression analysis will be utilised if the outcome variable is continuous. Generalised linear models (binomial distribution and logit link) will be utilised if the outcome variable is a proportion but with a binary outcome. The assumptions for these statistical tests will be investigated before running the tests. For all analysis, a p-value $<0.05$ will be considered statistically significant.

See Appendix 2 for the hypotheses that will be tested in this study.

\section{Independent variables:}

- Demographic: Age, Sex, ethnicity, Russell group vs non-Russell group university, stage of training, previous degree, part-time job, type of secondary school, parent's highest level of academic qualification, previous research experience, medical school decile

- Desire to get involved in various aspects of research (e.g. data collection, analysis, writing manuscript.): Categorical (yes/no). These components will be analysed separately. 
- Research perception: Continuous level (Likert scale)

\section{Dependent variables:}

- Research participation: analysed at categorical and continuous levels

- Publications: analysed at categorical and continuous levels. Secondary analysis will consider PubMed-indexed publications, number of first-authored publications, and collaborator status

- Presentations: analysed at categorical and continuous levels. Secondary analysis will consider oral presentations, and level of presentation (international or national: yes vs no).

- Grants: Proportion of successful grant applications (whilst still accounting for the number of applications)

- Confidence in various aspects of research: Analyse the individual Likert items as continuous variables in isolation

- Involvement in various aspects of components of research (e.g. data collection, analysis, writing manuscript.): Categorical (yes/no). These components will be analysed separately.

\section{Anticipated Outputs}

On completion of the study, the data will be analysed, and reports will be prepared. The study report(s) will be submitted for publication in peer-reviewed journal(s) and presented at national/ international meetings.

\section{Declarations}

\section{Conflict of interest: None}

\section{References}

1. General Medical Council (2020) Outcomes for graduates. https://www.gmcuk.org/-/media/documents/dc11326-outcomes-for-graduates-2018_pdf-75040796.pdf. Accessed 23 Nov 2020

2. Kosik RO, Tran DT, Fan APC, et al (2016) Physician Scientist Training in the United States: A Survey of the Current Literature. Eval Heal Prof 39:3-20. https://doi.org/10.1177/0163278714527290

3. Pusey C, Thakker R (2004) Clinical academic medicine: The way forward. Clin. Med. J. R. Coll. Physicians London 4:483-488

4. Pusey C, Thakker R (2005) Is there a future for academic medicine in the UK? Hosp. Med. 66:198199

5. Medical Schools Council (2018) Survey of Medical Clinical Academic Staffing Levels 2018. https://www.medschools.ac.uk/media/2491/msc-clinical-academic-survey-report-2018.pdf. Accessed 23 Nov 2020 
6. England NHS (2020) Research for all? An analysis of clinical participation in research

7. Cohen JJ, Gabriel BA, Terrell C (2002) The case for diversity in the health care workforce. Health Aff 21:90-102. https://doi.org/10.1377/hlthaff.21.5.90

8. Silberman EK, Belitsky R, Bernstein CA, et al (2012) Recruiting researchers in psychiatry: The influence of residency vs. Early motivation. Acad Psychiatry 36:85-90.

https://doi.org/10.1176/appi.ap.10010010

9. Waaijer CJF, Ommering BWC, van der Wurff LJ, et al (2019) Scientific activity by medical students: the relationship between academic publishing during medical school and publication careers after graduation. Perspect Med Educ 8:223-229. https://doi.org/10.1007/s40037-019-0524-3

10. Amgad M, Tsui MMK, Liptrott SJ, Shash E (2015) Medical student research: An integrated mixedmethods systematic review and meta-analysis. PLoS One 10:e0127470. https://doi.org/10.1371/journal.pone.0127470

11. Bhangu A, Kolias AG, Pinkney T, et al (2013) Surgical research collaboratives in the UK. Lancet 382:1091-1092

12. Ommering BWC, van Blankenstein FM, Waaijer CJF, Dekker FW (2018) Future physician-scientists: could we catch them young? Factors influencing intrinsic and extrinsic motivation for research among first-year medical students. Perspect Med Educ 7:248-255. https://doi.org/10.1007/s40037018-0440-y

13. Alamri Y, Qahwaji H, Saif S, Abu-Zaid A (2020) Research attitudes, barriers, and prior experience: Experience from interns working in Jeddah, Saudi Arabia. Avicenna J Med 10:118-121. https://doi.org/10.4103/ajm.ajm_173_19

14. Mills JMZ, Januszewski AS, Robinson BG, et al (2019) Attractions and barriers to Australian physician-researcher careers. Intern Med J 49:171-181. https://doi.org/10.1111/imj.14086

15. Al-Busaidi IS, Tarr GP (2018) Dissemination of results from medical student public health research training and factors associated with publication. Postgrad Med J 94:330-334. https://doi.org/10.1136/postgradmedj-2017-135361

16. Chetta MD, Sugg KB, Diaz-Garcia RJ, Kasten SJ (2017) Factors influencing American plastic surgery residents toward an academic career. Plast Surg 25:33-39. https://doi.org/10.1177/2292550317750146

17. Bonilla-Escobar FJ, Bonilla-Velez J, Tobón-García D, Ángel-Isaza AM (2017) Medical student researchers in Colombia and associated factors with publication: A cross-sectional study. BMC Med Educ 17. https://doi.org/10.1186/s12909-017-1087-9

18. Gouda P, O'Flynn S, Cantillon P (2018) Desires versus reality of medical and health science summer student research opportunities. Ir J Med Sci 187:817-820. https://doi.org/10.1007/s11845-017$1705-x$

19. Latham K, Dong T, Schreiber D, et al (2020) Uniformed Services University Medical Student Mentorship Experiences and Gender From 2010 to 2017. Mil Med. https://doi.org/10.1093/milmed/usaa064 
20. Bhatnagar V, Diaz S, Bucur PA (2020) The Need for More Mentorship in Medical School. Cureus. https://doi.org/10.7759/cureus.7984

21. Jones BD, Wilkins JLM (2013) Testing the MUSIC Model of Academic Motivation through confirmatory factor analysis. Educ Psychol. https://doi.org/10.1080/01443410.2013.785044

22. Sozio SM, Chan KS, Beach MC (2017) Development and validation of the Medical Student ScholarIdeal Mentor Scale (MSS-IMS). BMC Med Educ. https://doi.org/10.1186/s12909-017-0969-1

23. Klowak J, Elsharawi R, Whyte R, et al (2018) Predictors of medical student interest and confidence in research during medical school. Can Med Educ $\mathrm{J}$

24. Griffin MF, Hindocha S (2011) Publication practices of medical students at British medical schools: Experience, attitudes and barriers to publish. Med Teach. https://doi.org/10.3109/0142159X.2011.530320

25. Nikkar-Esfahani A, Jamjoom AAB, Fitzgerald JEF (2012) Extracurricular participation in research and audit by medical students: Opportunities, obstacles, motivation and outcomes. Med Teach. https://doi.org/10.3109/0142159X.2012.670324

26. Funston G, Piper RJ, Connell C, et al (2016) Medical student perceptions of research and researchorientated careers: An international questionnaire study. Med Teach. https://doi.org/10.3109/0142159X.2016.1150981

\section{Supplementary Files}

This is a list of supplementary files associated with this preprint. Click to download.

- Appendix1questionnaire.docx

- Appendix2hypotheses.docx 